Western University

Scholarship@Western

$5-1-2020$

\title{
Seizure freedom improves health-related quality of life after epilepsy surgery in children.
}

Puneet Jain

Mary Lou Smith

Kathy Speechley

kspeechl@uwo.ca

Mark Ferro

Mary Connolly

See next page for additional authors

Follow this and additional works at: https://ir.lib.uwo.ca/paedpub

Part of the Pediatrics Commons

\section{Citation of this paper:}

Jain, Puneet; Smith, Mary Lou; Speechley, Kathy; Ferro, Mark; Connolly, Mary; Ramachandrannair, Rajesh; Almubarak, Salah; Andrade, Andrea; and Widjaja, Elysa, "Seizure freedom improves health-related quality of life after epilepsy surgery in children." (2020). Paediatrics Publications. 521.

https://ir.lib.uwo.ca/paedpub/521 


\section{Authors}

Puneet Jain, Mary Lou Smith, Kathy Speechley, Mark Ferro, Mary Connolly, Rajesh Ramachandrannair, Salah Almubarak, Andrea Andrade, and Elysa Widjaja 


\title{
Seizure freedom improves health-related quality of life after epilepsy surgery in children
}

\author{
PUNEET JAIN ${ }^{1,2,3}$ | MARY LOU SMITH ${ }^{4}$ | KATHY SPEECHLEY5,6 | MARK FERRO7 | MARY CONNOLLY ${ }^{8}$ \\ RAJESH RAMACHANDRANNAIR ${ }^{9}$ SALAH ALMUBARAK ${ }^{10}$ | ANDREA ANDRADE $^{11}$ | ELYSA WIDJAJA ${ }^{12,13,14}$ (iD | \\ PEPSOOL STUDY TEAM*
}

1 Epilepsy Program, Division of Neurology, Department of Pediatrics, The Hospital for Sick Children, Toronto, Ontario, Canada. 2 Division of Pediatric Neurology, Department of Pediatrics, BLK Super Speciality Hospital, New Delhi, India. 3 Division of Pediatric Neurology, Department of Pediatrics, Danat Al Emarat Hospital for Women and Children, Abu Dhabi, UAE. 4 Department of Psychology, University of Toronto Mississauga, The Hospital for Sick Children, Toronto, Ontario; 5 Department of Paediatrics, Western University, London, Ontario; 6 Department of Epidemiology and Biostatistics, Western University, London, Ontario; 7 School of Public Health and Health Systems, University of Waterloo, Waterloo, Ontario; 8 Division of Neurology, Department of Pediatrics, BC Children's Hospital, Vancouver, British Columbia; 9 Department of Pediatrics, McMaster University, Hamilton, Ontario; 10 Division of Pediatric Neurology, Department of Pediatrics, University of Saskatchewan, Saskatoon; 11 Department of Pediatrics, London Health Sciences Center, University of Western Ontario, London, Ontario; 12 Division of Neurology, The Hospital for Sick Children, Toronto, Ontario; 13 Department of Diagnostic Imaging, The Hospital for Sick Children, Toronto, Ontario; 14 Institute for Health Policy Management and Evaluation, University of Toronto, Toronto, Ontario, Canada.

Correspondence to Elysa Widjaja, Department of Diagnostic Imaging, The Hospital for Sick Children, 555 University Avenue, Toronto, Ontario M5G 1X8, Canada. E-mail: Elysa.Widjaja@sickkids.ca

*Members of the Impact of Pediatric Epilepsy Surgery on Health-Related Quality of Life (PEPSOOL) study team can be found in the Acknowledgements. This article is commented on by Varadkar on pages $544-545$ of this issue.

\section{PUBLICATION DATA}

Accepted for publication 17th September 2019.

Published online 11th November 2019.

\section{ABBREVIATIONS}

DRE Drug-resistant epilepsy

HROLL Health-related quality of life

QOLCE Quality of Life in Childhood Epilepsy
AIM To determine whether epilepsy surgery improved health-related quality of life (HROoL) and whether seizure freedom after surgery mediated the improvement in HRQoL.

METHOD This multicenter cohort study compared HROoL after epilepsy surgery to pharmacological management in children with drug-resistant epilepsy (DRE). HRQoL was measured using the Quality of Life in Childhood Epilepsy (QOLCE) questionnaire at baseline and 1-year follow-up. The mediator between treatment type and HROLL was seizure freedom.

RESULTS Two hundred and thirty-seven patients were recruited (surgery group: $n=147$ [92 males, 45 females]; pharmacological group: $n=90$ [53 males, 37 females]). Mean age at seizure onset was 6 years (SD $4 \mathrm{y} 4 \mathrm{mo}$ ) in the surgical group and 6 years 1 month (SD $4 \mathrm{y}$ ) in the pharmacological group. The odds ratio of seizure freedom was higher for the surgery versus pharmacological group ( $\beta=4.24$ [95\% confidence interval $\{\mathrm{Cl}\}: 2.26-7.93], p<0.001$ ). Surgery had no direct effect on total QOLCE score at 1 -year $(\beta=0.24$ [95\% $\mathrm{Cl}-2.04$ to 2.51], $p=0.839$ ) compared to pharmacological management, but had an indirect effect on total QOLCE that was mediated by seizure freedom ( $\beta=0.92$ [95\% $\mathrm{Cl} 0.19-1.65], p=0.013$ ), adjusting for baseline total QOLCE score. Surgery had a direct effect on improving social function $(p=0.043)$, and an indirect effect on improving physical function $(p=0.016)$, cognition $(p=0.042)$, social function $(p=0.012)$ and behavior $(p=0.032)$, mediated by seizure freedom. INTERPRETATION Greater seizure freedom achieved through epilepsy surgery mediated the improvement in HRQoL compared to pharmacological management in children with DRE.
Health-related quality of life (HRQoL) is defined by the World Health Organization as a broad, multidimensional construct that includes a person's physical, psychological, and social well-being. Children with epilepsy have impairment in multiple domains of HRQoL, including higher rates of behavioural, cognitive, emotional, social, and academic disorders, compared to typically developing children or children with other chronic health conditions. ${ }^{1-5}$ HRQoL is considered to be a key patient-report outcome by the Patient-Centered Outcomes Research Institute and health regulatory agencies. ${ }^{6}$ Furthermore, HRQoL is regarded as a key measure for evaluating treatment efficacy by the International League Against Epilepsy. ${ }^{7}$

About $30 \%$ of patients with epilepsy have drug-resistant epilepsy (DRE), defined as failure of adequate trials of two tolerated and appropriate antiepileptic drugs. ${ }^{8}$ DRE can have devastating consequences on children, including impaired cognition, ${ }^{9}$ poor HRQoL, ${ }^{10,11}$ and 5 to 9 times' increased mortality, relative to the general population. ${ }^{12,13}$ Further, patients with DRE consume disproportionately more healthcare resources and have higher healthcare costs compared to patients with well-controlled epilepsy. ${ }^{14}$ 
Epilepsy surgery has been shown to improve seizure control in children with DRE. ${ }^{15}$ The American Academy of Neurology recommends epilepsy surgery for the treatment of focal DRE. ${ }^{16}$ As epilepsy affects multiple facets of the patients' lives, the traditional method of evaluating the success of epilepsy surgery, using a single clinical measure of seizure control, is inadequate. Therefore, HRQoL, which is multidimensional, is a highly appropriate patientcentred construct for evaluating the effectiveness of epilepsy surgery.

Existing studies exploring HRQoL in children after epilepsy surgery are few, and frequently lack a control group for comparison ${ }^{17-20}$ or do not measure baseline HRQoL. ${ }^{20-23}$ Further, there are discrepant findings on whether epilepsy surgery has a direct impact on HRQoL relative to medical therapy, and which domains of HRQoL improve with seizure freedom. ${ }^{15,23,24}$ The aims of this study were to determine whether epilepsy surgery improved HRQoL compared to pharmacological management in children with DRE, and whether seizure freedom mediated the improvement in HRQoL after treatment. The hypothesis was that epilepsy surgery was more likely to result in seizure-free outcome compared to pharmacological management and that seizure freedom mediated the improvement in overall HRQoL and multiple domains of HRQoL after epilepsy surgery.

\section{METHOD}

This multicenter, prospective cohort study recruited children aged 4 to 18 years with focal DRE between 2010 and 2017. All children had suspected focal epilepsy as assessed by clinical semiology and/or electroencephalography (EEG) and were being evaluated for epilepsy surgery candidacy. Exclusion criteria included previous epilepsy surgery, previous or planned palliative surgery (e.g. corpus callosotomy) or vagus nerve stimulator placement, neurometabolic disorders, neurodegenerative disorders, genetic epilepsy syndromes, and epileptic encephalopathies (not amenable to epilepsy surgery). All patients underwent detailed epilepsy surgery evaluation including: clinical history, physical examination, magnetic resonance imaging, video-EEG, and neuropsychological testing, supplemented by additional neurodiagnostic tests as deemed necessary. The decision to exclude a child from epilepsy surgery was made as part of clinical care for a variety of reasons, including inability to localize or lateralize a single epileptogenic focus and anticipated neurological deficits, such as hemiplegia or language impairment, if surgery were to proceed. In this study, the medical group was defined as those children with DRE who, after undergoing a standard diagnostic evaluation for epilepsy surgery candidacy, were deemed ineligible for surgery. All patients were assessed at baseline and at 1-year follow-up.

The study protocol was approved by the research ethics board of the participating hospitals and written informed consent and assent was obtained from parents and children with epilepsy. We followed the Strengthening the
What this paper adds

- Seizure freedom is higher after pediatric epilepsy surgery compared to pharmacologically managed epilepsy.

- Surgery indirectly improves health-related quality of life (HROoL) mediated by seizure freedom compared to pharmacological management.

- Surgery has a direct effect on improving social function relative to pharmacological management.

- Baseline HRQoL was an important predictor of HROoL after treatment.

Reporting of Observational Studies in Epidemiology (STROBE) guideline in this manuscript.

\section{Clinical factors}

Clinical data at baseline including age, sex, age at seizure onset, seizure frequency, seizure type (temporal or extratemporal lobe), seizure laterality, and number of antiepileptic drugs were obtained from the medical records. The IQ of all patients was assessed using the Wechsler Abbreviated Scale of Intelligence, Second Edition (for ages $6-18 \mathrm{y})^{25}$ or the Wechsler Preschool and Primary Scale of Intelligence, Fourth Edition (for ages $4-5 \mathrm{y})^{26}$

\section{Outcomes \\ Seizure control}

Seizure outcome at 1-year follow-up (1y after surgery in the surgical group and $1 \mathrm{y}$ after study enrolment in the pharmacological group) was assessed using the International League Against Epilepsy classification: Class 1, completely seizure-free; Class 2, only auras; Class 3, 1 to 3 seizure days per year; Class 4, 4 seizure days per year to $50 \%$ reduction in baseline number of seizure days; Class 5 , less than $50 \%$ reduction to $100 \%$ increase in baseline number of seizure days; and Class 6, greater than $100 \%$ increase in baseline number of seizure days. Seizure control was then categorized as seizure free or persistent seizures for subsequent analysis.

\section{HRQOL}

HRQoL was measured using the Quality of Life in Childhood Epilepsy (QOLCE) questionnaire. ${ }^{27}$ The QOLCE is a 76-item parent-rated instrument covering five domains (physical function, cognition, well-being, social function, and behavior) and 16 subscales. The total QOLCE score is the unweighted average of the 16 subscales, ranging from 0 to 100 . Higher scores indicate better HRQoL. This instrument has been reported to have good validity and reliability. ${ }^{27,28}$ QOLCE scores were recorded at baseline and at 1-year follow-up.

\section{Statistical analysis}

IBM SPSS version 23.0 (IBM Corporation, Armonk, NY, USA) was used for statistical analysis. All variables were screened for missing data and Little's Missing Completely at Random test was performed. The percentage of missing values for age at seizure onset and IQ were $1.7 \%$ and $6.3 \%$ respectively. There were no missing data for the other variables. Little's Missing Completely at Random 
test showed that data were missing completely at random $\left(\chi^{2}=0[d f=44], p=1.00\right)$. Subsequently, the fully conditional specification multiple imputation method (five imputations) was implemented. Pooled estimates of the five imputations were reported. Appropriate tests of significance ( $t$-test or $\chi^{2}$ test) were used to compare the means and proportions of the baseline clinical variables and baseline QOLCE scores for surgery and pharmacological management groups.

The baseline characteristics of children who were seizure free (irrespective of treatment) were compared to those with persistent seizures. A multivariable logistic regression model was used to predict seizure-free outcome. The independent variables included treatment, age, sex, age at seizure onset, number of antiepileptic drugs at baseline, seizure type, and IQ. Clinical variables that influenced seizure-free outcome were included in the mediation analysis.

The changes in total and domain QOLCE scores from baseline to 1-year were compared for the surgical and pharmacological groups using $t$-tests. Subsequently, a standard error of measurement-based criterion was used to define children with clinically meaningful changes in HRQoL from baseline to 1-year. When employing psychometrically robust measures of HRQoL, scores of at least 1 standard error of measurement are considered to represent a clinically important intraindividual change in HRQoL. ${ }^{29}$

A linear regression model was used to assess if seizurefree status predicted total QOLCE score at 1-year followup in the whole population, adjusting for baseline QOLCE score. Another linear regression model was conducted to assess if treatment predicted total QOLCE score at 1-year follow-up in all seizure-free patients, adjusting for baseline QOLCE score. A $p$-value of less than 0.05 was considered statistically significant.

\section{Mediation analysis}

Mediation analysis ${ }^{30}$ was done within a structural equation framework using Mplus version 8.1 (Muthen and Muthen, Los Angeles, CA, USA). We used maximum likelihood with robust estimation to evaluate if seizure-free outcome mediated the relationship between treatment (surgery vs pharmacological management) and total QOLCE score at 1-year follow-up, adjusting for baseline total QOLCE score. Both the direct and indirect effects of treatment on total QOLCE score at 1-year were measured. Subsequently, we evaluated if seizure-free outcome mediated the relationship between treatment and the five domains of HRQoL at 1-year follow-up, adjusting for each of the five baseline domains of HRQoL. Both the direct and indirect effects of treatment on the five domains of HRQoL at 1-year were measured. The adequacy of model fit was evaluated using the following statistics: Bentler's Comparative Fit Index (where $>0.900$ is acceptable); Tucker-Lewis Index (where $>0.900$ is acceptable); root mean square error of approximation (where $<0.08$ is acceptable). The $\chi^{2}$ test was not used for decisions of model fit as it is sensitive to sample size.

We conducted sensitivity analysis using a Bayesian analysis to determine whether seizure-free outcome mediated the relationship between treatment and HRQoL (both total and domains QOLCE scores) at 1-year follow-up, adjusting for the relevant baseline HRQoL. Conventional frequentist mediation analysis uses a normal approximation method to construct the confidence interval, whereby the standard error of the indirect effect is estimated by the first-order or second-order Taylor expansion. ${ }^{31,32}$ Bayesian analysis has the advantage of not imposing normality assumptions on the estimate of indirect effect ${ }^{33}$ and does not rely on large sample approximations. ${ }^{34}$

\section{RESULTS}

\section{Baseline characteristics}

Of the 237 children included in the study, 147 were in the surgical group (92 males, 45 females) and 90 in the pharmacological group (53 males, 37 females). Mean age at seizure onset was 6 years (standard deviation [SD] 4y 4mo) in the surgical group and 6 years 1 month (SD 4y) in the pharmacological group (Table 1). The median number of antiepileptic drugs was two (interquartile range: 1-2) in each group. Overall, 153 children (64.6\%) had daily or weekly seizures, which was more common in the surgical group (74.2\%) than in the pharmacological group (48.9\%). Temporal epilepsy was more common in the surgical group (40.1\%) and extratemporal epilepsy was more common in the pharmacological group $(73.3 \%)$.

The baseline mean total QOLCE score was higher in the surgical group (60.7 [95\% CI 58.6-62.8]) than the pharmacological group (56.6 [95\% CI 53.7-59.4]). Physical function and cognition were also higher in the surgical group (Table 1, Fig. 1). The baseline total QOLCE score had a Cronbach's alpha of 0.962 .

\section{Seizure-free outcome at 1-year}

The rate of seizure freedom at 1-year follow-up was significantly higher in the surgical group (88/147 [59.9\%]) compared to the pharmacological group (28/90 [31.1\%]) $(p<0.001)$. International League Against Epilepsy seizure outcomes for the two groups are summarized in Table S1 (online supporting information). The baseline characteristics of children who were seizure-free were similar to those with persistent seizures in the pharmacological group (Table S2, online supporting information).

Multivariable logistic regression showed that surgery was associated with seizure-free outcome more frequently than pharmacological management (odds ratio $=4.24$ [95\% CI 2.26-7.93], $p<0.001$ ) (Table S3, online supporting information). Age, sex, age at seizure onset, seizure type (temporal vs extra-temporal), number of antiepileptic drugs, and IQ at baseline did not predict seizure freedom (all $p>0.05$ ). Hence, these variables were not included in the mediation analysis. 


\begin{tabular}{|c|c|c|c|}
\hline & Surgical ( $n=147)$ & Pharmacological $(n=90)$ & $p$ \\
\hline Mean (SD) age at enrolment, y:mo & $11: 8(4: 4)$ & $10: 9(3: 11)$ & 0.06 \\
\hline Males/females, $n$ & $92 / 45$ & $53 / 37$ & 0.57 \\
\hline Mean (SD) age at seizure onset, y:mo & $6: 0(4: 4)$ & $6: 2(4: 0)$ & 0.74 \\
\hline Antiepileptic drugs, median (IQR) & $2(1-2)$ & $2(1-2)$ & 0.37 \\
\hline IQ, mean (SD) & $85.41(20.01)$ & $87.13(18.54)$ & 0.51 \\
\hline \multicolumn{4}{|l|}{ Seizure frequency at baseline, $n(\%)$} \\
\hline Daily/weekly & 109 (74.15) & $44(48.89)$ & \multirow[t]{2}{*}{0.002} \\
\hline Monthly or less & $38(25.85)$ & $46(51.11)$ & \\
\hline \multicolumn{4}{|l|}{ Seizure laterality, $n(\%)$} \\
\hline Left & 77 (52.38) & $36(45)$ & \multirow[t]{3}{*}{$<0.001$} \\
\hline Right & $69(46.94)$ & $30(37.5)$ & \\
\hline Bilateral & $1(0.68)$ & $14(17.5)$ & \\
\hline \multicolumn{4}{|l|}{ Seizure type, $n(\%)$} \\
\hline Temporal & $59(40.14)$ & $24(26.67)$ & \multirow[t]{2}{*}{0.035} \\
\hline Extra-temporal & $88(59.86)$ & $66(73.33)$ & \\
\hline \multicolumn{4}{|l|}{ Type of surgery, $n(\%)$} \\
\hline Lobectomy & $54(36.74)$ & & \\
\hline Lesionectomy/tailored focal resection & $52(35.37)$ & & \\
\hline Multi-lobar resection & $35(23.81)$ & & \\
\hline Hemispherectomy & $6(4.08)$ & & \\
\hline \multicolumn{4}{|l|}{ QOLCE score at baseline, mean (SD) } \\
\hline Physical & $55.84(17.99)$ & $51.04(16.93)$ & 0.043 \\
\hline Social & $52.19(14.84)$ & $48.93(16.28)$ & 0.116 \\
\hline Cognition & $64.95(20.11)$ & $54.44(21.39)$ & $<0.001$ \\
\hline Well-being & $69.23(15.50)$ & $69.34(15.11)$ & 0.826 \\
\hline Behavior & $61.18(13.52)$ & $58.99(13.46)$ & 0.228 \\
\hline Total QOLCE score & $60.68(12.71)$ & $56.55(13.58)$ & 0.019 \\
\hline
\end{tabular}

Bold type indicates statistical significance. SD, standard deviation; IQR, interquartile range (Q3-Q1); QOLCE, Quality of Life in Childhood Epilepsy.

Histology in the surgical group included cortical malformations ( $n=49$ patients), tuberous sclerosis $(n=6)$, tumors $(n=27)$, mesial temporal sclerosis $(n=15)$, gliosis $(n=36)$, and others $(n=14)$ (Table S4, online supporting information).

\section{Change in OOLCE scores}

In the surgical group, the mean total QOLCE scores at baseline and 1-year follow-up were 60.7 (95\% CI 58.662.8 ) and 63.2 (95\% CI 61.2-65.1) respectively ( $p=0.001$ ). Physical function, social function, and behavior at 1 -year were significantly higher compared to baseline $(p<0.05)$, but there were no significant differences in cognition and well-being at 1 -year relative to baseline $(p>0.05)$ (Table 2, Fig. 1).

In the pharmacological group, the mean total QOLCE scores at baseline and 1-year follow-up were 56.6 (95\% CI 53.7-59.4) and 59.0 (95\% CI 56.1-62.0) respectively $(p=0.010)$. Physical function and behavior at 1 -year were significantly higher compared to baseline $(p<0.05)$, but cognition, well-being, and social function were not significantly improved at 1-year relative to baseline $(p>0.05)$.

Forty-nine $(33.3 \%)$ children in the surgical group and $33(36.7 \%)$ in the pharmacological group showed clinically meaningful increases $(>1$ standard error of measurement) in total QOLCE score $(p=0.60)$ (Table S5, online supporting information).

Seizure freedom ( $\beta=3.26$ [95\% CI 1.1-5.40], $p=0.003$ ) was associated with higher total QOLCE score at 1-year follow-up, when baseline total QOLCE score was included as a covariate $(\beta=0.72[95 \%$ CI $0.64-0.81], p<0.001)$ in the whole sample. In the subgroup who were seizure-free $(n=116)$, treatment (pharmacological or surgical) $(\beta=1.50$ [95\% CI -1.68 to 4.69$], p=0.35$ ) was not associated with a higher total QOLCE score at 1-year follow-up, when baseline total QOLCE score was included as a covariate $(\beta=0.73$ [95\% CI 0.62-0.84], $p<0.001)$.

\section{Mediation analysis}

The model fit for mediation analysis of seizure freedom on the relationship between treatment type and QOLCE scores (total and domain QOLCE scores) was adequate (Table S6, online supporting information).

\section{Total QOLCE score}

Treatment type (surgery vs pharmacological management) did not directly affect total QOLCE score at 1-year follow-up ( $\beta=0.24$ [95\% CI -2.04 to 2.51], $p=0.839$ ) (Fig. 2, Table 3). Seizure freedom $(\beta=3.20$ [95\% CI $1.03-5.36]$, $p=0.004)$ and baseline total QOLCE score ( $\beta=0.72[95 \%$ CI $0.65-0.80], p<0.001)$ were significantly associated with total QOLCE score at 1-year follow-up. Surgery was associated with a seizure-free outcome more frequently than pharmacological management ( $\beta=0.29$ [95\% CI 0.16-0.41], $p<0.001)$.

There was a significant indirect effect of surgery relative to pharmacological management on improving total QOLCE score at 1-year, through improved seizure free$\operatorname{dom}(\beta=0.92$ [95\% CI $0.19-1.65], p=0.013)$, adjusting for baseline total QOLCE score. 


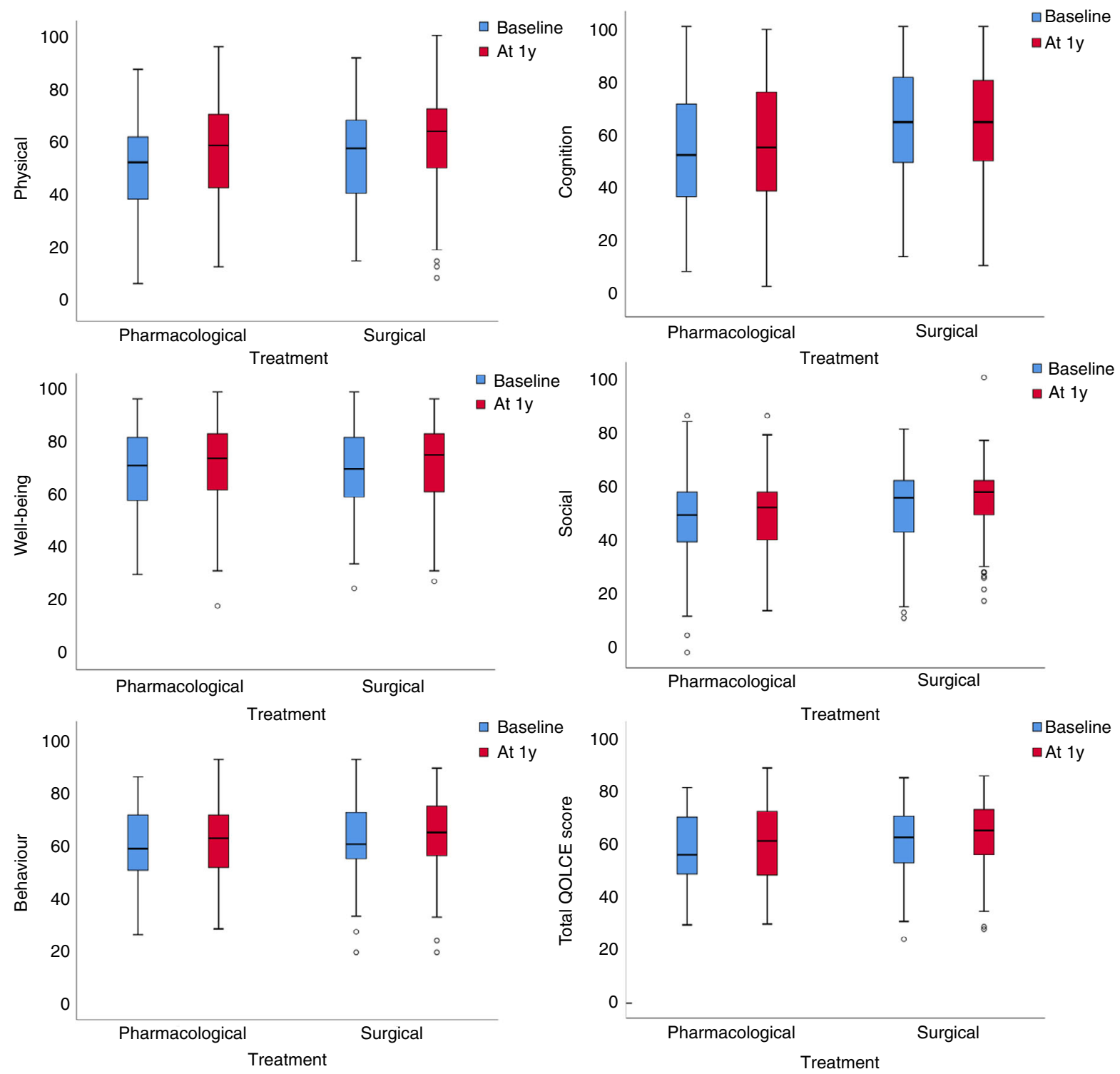

Figure 1: Box plots showing distribution of total Quality of Life in Childhood Epilepsy (00LCE) score and five domains (physical, cognition, well-being, social, and behaviour) scores at baseline and 1-year follow-up in both surgical and pharmacological groups. [Colour figure can be viewed at wileyon linelibrary.com]

Table 2: Total Quality of Life in Childhood Epilepsy (QOLCE) and domain scores at baseline and 1-year for epilepsy surgery and pharmacological management

\begin{tabular}{|c|c|c|c|c|c|c|}
\hline & \multicolumn{3}{|c|}{ Surgical group ( $n=147)$} & \multicolumn{3}{|c|}{ Pharmacological group $(n=90)$} \\
\hline & Baseline & 1-year & $p$ & Baseline & 1-year & $p$ \\
\hline Physical function & $55.84(52.91-58.77)$ & $60.64(57.74-63.54)$ & $<0.001$ & $51.04(47.49-54.59)$ & $57.01(52.84-61.18)$ & $<0.001$ \\
\hline Cognition & 64.95 (61.67-68.23) & $64.38(61.00-67.76)$ & 0.696 & $54.44(49.96-58.92)$ & $56.29(51.46-61.12)$ & 0.207 \\
\hline Well-being & $69.23(66.70-71.76)$ & $71.14(68.67-73.61)$ & 0.065 & $69.34(66.17-72.51)$ & $70.70(67.68-73.72)$ & 0.281 \\
\hline Social function & $52.19(49.77-54.61)$ & $55.79(53.82-57.76)$ & 0.004 & $48.93(45.52-52.34)$ & $49.98(46.87-53.09)$ & 0.404 \\
\hline Behavior & $61.18(58.98-63.38)$ & $63.81(61.63-65.99)$ & 0.003 & 58.99 (56.17-61.81) & 61.09 (58.35-63.83) & 0.031 \\
\hline Total QOLCE score & $60.68(58.61-62.75)$ & $63.15(61.21-65.09)$ & 0.001 & 56.55 (53.71-59.29) & $59.02(56.08-61.96)$ & 0.010 \\
\hline
\end{tabular}

Data are mean (95\% confidence interval). 


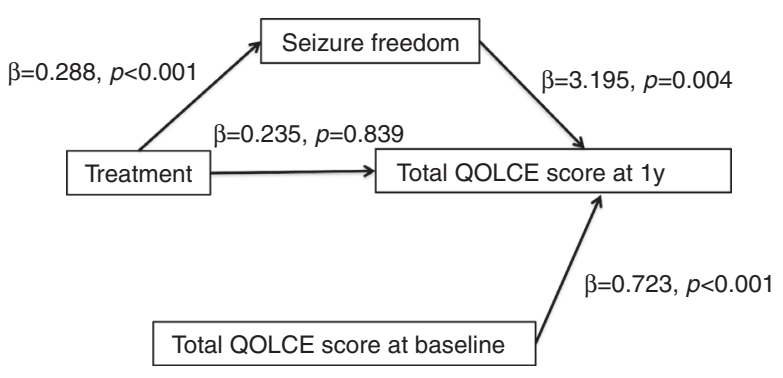

Figure 2: The relationship between treatment (surgery vs pharmacological management) and total Quality of Life in Childhood Epilepsy (OOLCE) score at 1-year follow-up is mediated by seizure control, adjusting for baseline total QOLCE score.

\section{Domains of QOLCE}

Surgery had a direct effect on improving social function relative to pharmacological management $(\beta=3.13[95 \%$ CI 0.10-6.16], $p=0.043$ ) (Table 3). However, treatment type (surgery vs pharmacological management) had no direct effect on physical function, well-being, cognition, or behavior (all $p>0.05$ ). Seizure freedom was associated with improved physical function $(\beta=5.51$ [95\% CI 1.67-9.36], $p=0.005)$, cognition ( $\beta=4.72$ [95\% CI $0.60-8.84], p=0.025$ ), social function ( $\beta=4.67$ [95\% CI 1.61-7.73], $p=0.003)$, and behavior $(\beta=2.95$ [95\% CI 0.56-5.35], $p=0.016$ ), but not with well-being ( $\beta=0.89$ [95\% CI 1.94-3.72], $p=0.538)$ at 1-year follow-up. Physical function, well-being, cognition, social function, and behavior at baseline predicted the corresponding domains at 1 -year follow-up (all $p<0.001$ ).

Surgery had a significant indirect effect on improving physical function ( $\beta=1.59$ [95\% CI 0.30-2.88], $p=0.016$ ), cognition ( $\beta=1.36$ [95\% CI 0.05-2.67], $p=0.042$ ), social function $(\beta=1.34$ [95\% CI $0.30-2.39], p=0.012)$, and behavior $(\beta=0.85$ [95\% CI $0.07-1.63], p=0.032$ ), which was mediated through seizure freedom, after adjusting for baseline physical function, cognition, social function, and behavior respectively. However, there was no significant indirect effect of treatment type on improving well-being $(\beta=0.26$ [95\% CI 0.5-1.07], $p=0.541)$.

\section{Sensitivity analysis}

Bayesian analysis showed similar findings (Table S7, online supporting information). There was no direct effect of treatment type on total QOLCE score at 1-year. Seizure freedom and higher baseline total QOLCE score were associated with higher total QOLCE score at 1-year. Surgery was associated with higher seizure-free outcome than pharmacological management. Seizure freedom mediated the relationship between surgery and higher total QOLCE score at 1-year, adjusting for baseline total QOLCE score.

There was no direct effect of treatment type on physical function, well-being, cognition, social function, and behavior. Seizure freedom also mediated the relationship between surgery and higher physical function, social function, and behavior, adjusting for baseline physical function, social function, and behavior respectively.

\section{DISCUSSION}

This is the largest study assessing HRQoL in children with DRE after epilepsy surgery compared to pharmacological management. We used a structural equation framework to tease out the direct and indirect effects of treatment on HRQoL. We showed that treatment type did not have a direct effect on overall HRQoL, but that seizure-free outcome mediated the improvement in HRQoL after epilepsy surgery. Our findings mirror other studies, which demonstrated that children who were seizure-free after surgery had higher HRQoL than those with persistent seizures. ${ }^{17-20,35}$ These studies compared the HRQoL amongst surgical patients who were seizure-free relative to those who were not, but did not include a pharmacological control group or conduct a mediation analysis.

Our findings suggest that some, but not all, domains of HRQoL improve with seizure freedom after surgery. In our study, children who were seizure-free after surgery showed improvements in most domains of HRQoL, including physical function, cognition, social function, and behavior, but not with well-being. Others also showed improvement in physical function, ${ }^{17-20}$ cognition, ${ }^{17,18,20,21,36}$ and social function ${ }^{18-21,28}$ with seizure freedom. However, there was lack of consensus with respect to changes in behavior and well-being after surgery amongst those who were seizure-free, with some reporting no change in behaviour ${ }^{17,18}$ or well-being ${ }^{18,19,21}$ and others reporting an improvement in behaviour ${ }^{19,22}$ or wellbeing. ${ }^{20,36,37}$ Potential reasons for the lack of consensus in findings could be related to small sample size, ${ }^{17,23}$ use of variable HRQoL instruments, lack of a pharmacological comparison group, ${ }^{17-20}$ or lack of presurgical baseline HRQoL measurements. ${ }^{20-23}$

Table 3: Mediating effect of seizure freedom on the relationship between treatment (surgery vs pharmacological management) and health-related quality of life (HROoL) ${ }^{a}$ at 1-year adjusting for baseline $\mathrm{HROOL}^{\mathrm{a}}$

\begin{tabular}{|c|c|c|c|c|}
\hline & Baseline score & Seizure freedom & Direct effect of treatment & Indirect effect of treatment \\
\hline Total QOLCE score & $0.723(0.648-0.799)$ & 3.195 (1.033-5.358) & $0.235(-2.037$ to 2.507$)$ & $0.919(0.191-1.647)$ \\
\hline Physical & $0.609(0.510-0.708)$ & 5.513 (1.669-9.358) & $-0.877(-4.871$ to 3.117$)$ & $1.585(0.296-2.875)$ \\
\hline Cognition & $0.668(0.581-0.756)$ & $4.719(0.603-8.835)$ & $-0.291(-4.457$ to 3.875$)$ & $1.357(0.047-2.666)$ \\
\hline Well-being & $0.583(0.491-0.675)$ & $0.889(-1.940$ to 3.718$)$ & $0.248(-2.589$ to 3.085$)$ & $0.256(-0.563$ to 1.074$)$ \\
\hline Social function & $0.410(0.317-0.504)$ & $4.672(1.614-7.730)$ & $3.132(0.099-6.164)$ & $1.343(0.300-2.387)$ \\
\hline Behavior & $0.628(0.548-0.708)$ & $2.954(0.562-5.346)$ & $0.499(-1.870$ to 2.867$)$ & $0.849(0.071-1.627)$ \\
\hline
\end{tabular}

Data are $\beta$ (95\% confidence interval). ${ }^{a}$ Total Quality of Life in Childhood Epilepsy (QOLCE) and domain scores. 
There were discrepant findings in the literature as to whether pediatric epilepsy surgery has a direct effect on improving overall HRQoL. In a single-center randomized controlled trial, Dwivedi et al. ${ }^{15}$ found an increase in total HRQoL after surgery but not pharmacological management, with a significant between-group difference. In their study, surgery achieved a higher seizure-free rate, and pharmacological therapy yielded a lower seizure-free rate, relative to our cohort. The larger difference in seizure-free outcome may have contributed to the higher overall HRQoL in the surgical group relative to the pharmacological group. Two other studies also found an increase in overall HRQoL, ${ }^{38}$ physical activities, ${ }^{38}$ cognition, ${ }^{39}$ social activities, ${ }^{38}$ and self-perceived competence ${ }^{39}$ in the surgical group at follow-up compared to baseline, but these studies did not include a pharmacological comparison group. Mikati et al. ${ }^{23}$ did not identify an improvement in total QOLCE score, general health, social function, cognition, well-being, or physical function, but found an improvement in behaviour in the surgical group compared to the pharmacological group. In our study, we found that surgery had a direct effect on improving social function compared to pharmacological management, after adjusting for baseline social function and seizure control. Differences in findings could be related to patient populations and the instruments used to assess HRQoL.

The proportion of seizure-free outcome amongst the surgical and pharmacological groups in our study was within the range reported in observational studies. ${ }^{21,23,36,40-45}$ We have included children with a variety of pathologies and different types of seizures (temporal vs extra-temporal), which reflects the 'real-world' phenomenon of pediatric epilepsy surgery that is often characterized by heterogeneous underlying etiology and seizure location. Two meta-analyses, primarily from surgical uncontrolled studies, showed that the seizure-free rate for pediatric extra-temporal epilepsy $(56 \%)^{46}$ was lower than for temporal epilepsy $(76 \%) .{ }^{47}$ We did not identify a difference in seizure-free outcome amongst those with temporal vs extra-temporal epilepsy. Other research also did not identify a significant difference in seizure-free outcome between temporal and extra-temporal epilepsy. ${ }^{48}$

An additional contribution of our study was in identifying baseline HRQoL, both total and domains QOLCE scores, as an important predictor of HRQoL at 1-year follow-up, irrespective of treatment type. Sabaz et al. ${ }^{17}$ also found that baseline HRQoL was a significant predictor of change in HRQoL. This finding highlights the importance of optimizing baseline HRQoL and represents a potential target for future intervention.

Limitations of this study included a relatively short-term (1y) follow-up after epilepsy surgery. Longer follow-up is required to determine if the trajectory of HRQoL changes over time after surgery, and whether domain(s) of HRQoL that did not change at 1-year could change with longer follow-up. However, in long-term follow-up studies of patients with childhood-onset DRE, duration of follow-up after surgery did not influence HRQoL. ${ }^{10,21}$ Second, we did not consider other factors such as patient mood, caregiver factors, and family function that could potentially influence HRQoL after surgery. Patient mood, including depression and anxiety, was previously shown to be an important predictor of HRQoL after surgery. ${ }^{10,21}$ Family variables such as fewer family resources, caregiver mood, and caregiver unemployment were shown to be associated with diminished HRQoL in children with DRE. ${ }^{11}$ The contributions of caregiver and family factors on influencing change in HRQoL after treatment represent a potential area for future research. Third, we did not include children with DRE below the age of 4 years, as there is no validated instrument to measure HRQoL below this age. It is possible that younger children stand to benefit more from epilepsy surgery, as recurrent seizures have a shorter duration of impact on their development than older age at surgery. ${ }^{41}$ Fourth, the control group comprised patients who underwent epilepsy surgery evaluation and were considered not suitable candidates for surgery due to inability to localize the seizure focus. The selection of medical controls based on their suitability for surgical treatment could have confounded the findings. However, a previous randomized controlled trial has demonstrated similar findings, in that epilepsy surgery achieved a higher seizure-free and HRQoL outcome than medical therapy. ${ }^{15}$ Other studies on surgical outcomes have used the same strategy that we used in the selection of a control group. ${ }^{10,40,44,49-51}$ These studies, and our study, have demonstrated that the two groups did not differ in their baseline characteristics including age, sex, seizure-related clinical variables, and cognitive and psychosocial function.

The present study provided strong evidence that greater seizure freedom achieved through epilepsy surgery mediated the improvement in HRQoL, in both overall and multiple domains, compared to pharmacological management in children with DRE. We also found that baseline HRQoL was an important predictor of HRQoL after treatment, emphasizing the importance of optimizing baseline HRQoL to enhance improvement in HRQoL with treatment.

\section{ACKNOWLEDGEMENTS}

The members of the Impact of Pediatric Epilepsy Surgery on Health-Related Quality of Life (PEPSQOL) study team are as follows: O Carter Snead III and Cristina Go (both Epilepsy Program, Division of Neurology, Department of Pediatrics, The Hospital for Sick Children, Toronto, Ontario, Canada). PEPSQOL was funded by a grant from the Canadian Institutes of Health Research (MOP-133708). The authors have stated that they had no interests which might be perceived as posing a conflict or bias.

\section{SUPPORTING INFORMATION}

The following additional material may be found online:

Table S1: International League Against Epilepsy seizure outcomes in the study population 
Table S2: Baseline characteristics of the study participants in the pharmacological treatment group

Table S3: Multivariable logistic regression model to predict seizure-free outcome at 1-year

Table S4: Etiology of epilepsy in the surgical group

Table S5: Children with clinically meaningful changes in health-related quality of life from baseline to 1-year based on standard error of measurement
Table S6: Model fit for mediation analysis of seizure freedom on the relationship between treatment type and Quality of Life in Childhood Epilepsy scores

Table S7: Bayesian analysis to explore the mediating effect of seizure freedom on the relationship between treatment and health-related quality of life at 1-year

\section{REFERENCES}

1. Austin JK. Comparison of child adaptation to epilepsy and asthma. 7 Child Adolesc Psychiatr Ment Health Nurs 1989; 2: 139-44.

2. Austin JK, Huster GA, Dunn DW, Risinger MW. Adolescents with active or inactive epilepsy or asthma: a comparison of quality of life. Epilepsia 1996; 37: 1228 38.

3. Austin JK, Risinger MW, Beckett LA. Correlates of behavior problems in children with epilepsy. Epilepsia 1992; 33: 1115-22.

4. Dunn DW, Austin JK, Huster GA. Symptoms of depression in adolescents with epilepsy. $7 \mathrm{Am}$ Acad Child Adolesc Psycbiatry 1999; 38: 1132-8.

5. Williams J, Steel C, Sharp GB, et al. Parental anxiety and quality of life in children with epilepsy. Epilepsy Behav 2003; 4: 483-6.

6. U.S. Department of Health and Human Services FDA Center for Drug Evaluation and Research; U.S. Department of Health and Human Services FDA Center for Biologics Evaluation and Research; U.S. Department of Health and Human Services FDA Center for Devices and Radiological Health. Guidance for industry: patient-reported outcome measures: use in medical product development to support labeling claims: draft guidance. Health Qual Life Outcomes 2006; 4: 79.

7. Thurman DJ, Beghi E, Begley CE, et al. Standards for epidemiologic studies and surveillance of epilepsy. Epilepsia 2011; 52(Suppl 7): 2-26.

8. Kwan P, Arzimanoglou A, Berg AT, et al. Definition of drug resistant epilepsy: consensus proposal by the ad hoc Task Force of the ILAE Commission on Therapeutic Strategies. Epilepsia 2010; 51: 1069-77.

9. Hrabok M, Sherman EM, Bello-Espinosa L, Hader W. Memory and health-related quality of life in severe pediatric epilepsy. Pediatrics 2013; 131: e525-32.

10. Elliott I, Kadis DS, Lach L, et al. Quality of life in young adults who underwent resective surgery for epilepsy in childhood. Epilepsia 2012; 53: 1577-86.

11. Conway L, Smith ML, Ferro MA, et al. Correlates of health-related quality of life in children with drug resistant epilepsy. Epilepsia 2016; 57: 1256-64.

12. Berg AT, Shinnar S, Testa FM, Levy SR, Smith SN, Beckerman B. Mortality in childhood-onset epilepsy. Arch Pediatr Adolesc Med 2004; 158: 1147-52.

13. Camfield CS, Camfield PR, Veugelers PJ. Death in children with epilepsy: a population-based study. Lancet 2002; 359: 1891-5.

14. Manjunath R, Paradis PE, Parisé H, et al. Burden of uncontrolled epilepsy in patients requiring an emergency room visit or hospitalization. Neurology 2012; 79: 1908-16.

15. Dwivedi R, Ramanujam B, Chandra PS, et al. Surgery for drug-resistant epilepsy in children. $N$ Engl 7 Med 2017; 377: 1639-47.

16. Engel J Jr, Wiebe S, French J, et al. Practice parameter: temporal lobe and localized neocortical resections for epilepsy: report of the Quality Standards Subcommittee of the American Academy of Neurology, in association with the American Epilepsy Society and the American Association of Neurological Surgeons. Neurology 2003; 60: $538-47$.

17. Sabaz M, Lawson JA, Cairns DR, et al. The impact of epilepsy surgery on quality of life in children. Neurology 2006; 66: 557-61.

18. Zupanc ML, Rubio EJ, Werner RR, et al. Epilepsy surgery outcomes: quality of life and seizure control. Pediatr Neurol 2010; 42: 12-20.

19. Conway L, Widjaja E, Smith ML. Impact of resective epilepsy surgery on health-related quality of life in children with and without low intellectual ability. Epilepsy Behav 2018; 83: 131-6.

20. Keene DL, Higgins MJ, Ventureyra EC. Outcome and life prospects after surgical management of medically intractable epilepsy in patients under 18 years of age. Childs Nerv Syst 1997; 13: 530-5.

21. Puka K, Smith ML. Predictors of long-term quality of life after pediatric epilepsy surgery. Epilepsia 2015; 56: 873-81.

22. Puka K, Smith ML. Long-term outcomes of behavior problems after epilepsy surgery in childhood. 7 Neurol 2016; 263: 991-1000.

23. Mikati MA, Rahi AC, Shamseddine A, Mroueh S, Shoeib H, Comair Y. Marked benefits in physical activity and well-being, but not in functioning domains, 2 years after successful epilepsy surgery in children. Epilepsy Behav 2008; 12: 145-9.

24. Griffiths SY, Sherman EM, Slick DJ, Eyrl K, Connolly MB, Steinbok P. Postsurgical health-related quality of life (HRQoL) in children following hemispherectomy for intractable epilepsy. Epilepsia 2007; 48: 564-70.

25. Wechsler D. Wechsler Abbreviated Scale of Intelligence (WASI) manual. San Antonio, TX: The Psychological Corporation, 2011.

26. Wechsler D. Technical and Interpretive Manual for the Wechsler Preschool and Primary Scale of Intelligence. San Antonio, TX: The Psychological Corporation, 2012.

27. Sabaz M, Cairns DR, Lawson JA, Nheu N, Bleasel AF, Bye AM. Validation of a new quality of life measure for children with epilepsy. Epilepsia 2000; 41: 765-74.
28. Sabaz M, Lawson JA, Cairns DR, et al. Validation of the quality of life in childhood epilepsy questionnaire in American epilepsy patients. Epilepsy Behav 2003; 4: 680-91.

29. Wyrwich KW, Tierney WM, Wolinsky FD. Further evidence supporting an SEM-based criterion for identifying meaningful intra-individual changes in health-related quality of life. 7 Clin Epidemiol 1999; 52: 861-3.

30. MacKinnon DP. Introduction to Statistical Mediation Analysis. New York, NY: Taylor \& Francis Group/ Lawrence Erlbaum Associates, 2008.

31. Aroian L. The probability function of the product of two normally distributed variables. Ann Math Stat 1947; 18: $265-71$.

32. Sobel M. Asymptotic confidence intervals for indirect effects in structural equation models. In: Leinhardt S, editor. Sociological Methodology. Washington, DC: American Sociological Association, 1982: 290-312.

33. Yuan Y, MacKinnon DP. Bayesian mediation analysis. Psychol Methods 2009; 14: 301-22.

34. Robert C. The Bayesian Choice: From Decision-theoretic Foundations to Computational Implementation, 2nd ed. New York, NY: Springer Verlag, 2007.

35. Dagar A, Chandra PS, Chaudhary K, et al. Epilepsy surgery in a pediatric population: a retrospective study of 129 children from a tertiary care hospital in a developing country along with assessment of quality of life. Pediatr Neurosurg 2011; 47: 186-93.

36. Sibilia V, Barba C, Metitieri T, et al. Cognitive outcome after epilepsy surgery in children: a controlled longitudinal study. Epilepsy Behav 2017; 73: 23-30.

37. Tavares TP, Puka K, Smith ML. Emotional functioning: Long-term outcomes after pediatric epilepsy surgery. Epilepsia 2015; 56: 745-53.

38. Titus JB, Lee A, Kasasbeh A, et al. Health-related quality of life before and after pediatric epilepsy surgery: the influence of seizure outcome on changes in physical functioning and social functioning. Epilepsy Bebav 2013; 27: $477-83$.

39. van Empelen R, Jennekens-Schinkel A, van Rijen PC, Helders PJ, van Nieuwenhuizen O. Health-related quality of life and self-perceived competence of children assessed before and up to two years after epilepsy surgery. Epilepsia 2005; 46: 258-71.

40. Edelvik A, Rydenhag B, Olsson I, et al. Long-term outcomes of epilepsy surgery in Sweden: a national prospective and longitudinal study. Neurology 2013; 81: 1244-51.

41. Otsuki T, Kim HD, Luan G, et al. Surgical versus medical treatment for children with epileptic 
encephalopathy in infancy and early childhood: Results of an international multicenter cohort study in Far-East Asia (the FACE study). Brain Dev 2016; 38: 449-60.

42. Oldham MS, Horn PS, Tsevat J, Standridge S. Costs and clinical outcomes of epilepsy surgery in children with drug-resistant epilepsy. Pediatr Neurol 2015; 53: 216-20.

43. Sinclair DB, Aronyk K, Snyder T, et al. Extratemporal resection for childhood epilepsy. Pediatr Neurol 2004; 30: $177-85$.

44. Skirrow C, Cross JH, Cormack F, Harkness W, Vargha-Khadem F, Baldeweg T. Long-term intellectual outcome after temporal lobe surgery in childhood. Neurology 2011; 76: 1330-7.
45. Teutonico F, Mai R, Devinsky O, et al. Epilepsy surgery in tuberous sclerosis complex: early predictive elements and outcome. Childs Nerv Syst 2008; 24: 143745.

46. Englot DJ, Breshears JD, Sun PP, Chang EF, Auguste KI. Seizure outcomes after resective surgery for extratemporal lobe epilepsy in pediatric patients. 7 Neurosurg Pediatr 2013; 12: 126-33.

47. Englot DJ, Rolston JD, Wang DD, Sun PP, Chang $\mathrm{EF}$, Auguste KI. Seizure outcomes after temporal lobectomy in pediatric patients. 7 Neurosurg Pediatr 2013; 12: 134-41.

48. Rubinger L, Chan C, D'Arco F, et al. Change in presurgical diagnostic imaging evaluation affects subse- quent pediatric epilepsy surgery outcome. Epilepsia 2016; 57: 32-40.

49. Mikati MA, Ataya N, Ferzli J, et al. Quality of life after surgery for intractable partial epilepsy in children: a cohort study with controls. Epilepsy Res 2010; 90: $207-$ 13.

50. Markand ON, Salanova V, Whelihan E, Emsley CL. Health-related quality of life outcome in medically refractory epilepsy treated with anterior temporal lobectomy. Epilepsia 2000; 41: 749-59.

51. Smith ML, Elliott IM, Lach L. Cognitive skills in children with intractable epilepsy: comparison of surgical and nonsurgical candidates. Epilepsia 2002; 43: $631-7$.

\section{New from Mac Keith Press}

\section{Practical Guide}

\section{Children and Youth with Complex Cerebral Palsy}

\section{Care and Management}

\section{Edited by Laurie Glader and Richard Stevenson}

- Provides useful summary points of key recommendations at the end of each chapter.

- Includes Clinical Care Tools to guide clinicians in evaluation, preventive care and crisis management

- Care Tools include a Medical Review Supplement, Equipment and Services Checklist and an ICF-Based Care: Goals and Management Form.

November 2018 / 240 x 170mm / 288 pp / Softback / ISBN 978-1-909962-98-9 / £39.95

www.mackeith.co.uk/shop 


\section{RESUMEN}

La ausencia de crises epilépticas en niños mejora la calidad de vida relacionada con la salud después de la cirugía de epilepsia

\section{OBJETIVO}

Determinar si la cirugía de epilepsia mejora la calidad de vida relacionada con la salud (HROoL) y si la ausencia de crises epilépticas después de la cirugía intervino en la mejora.

\section{METODO}

Estudio de cohorte, multicéntrico que evaluó la HRQoL después de la cirugía de epilepsia comparándolo con el manejo farmacológico, en niños con epilepsia farmacorresistente (DRE). La HRQoL se midió utilizando el cuestionario de calidad de vida en la infancia (QOLCE) al inicio y después de un año de seguimiento. El mediador entre el tipo de tratamiento y HRQoL fue la ausencia de crises epilépticas.

\section{RESULTADOS}

Se reclutaron 237 pacientes (grupo de cirugía: $n 147$ [92 varones, 45 mujeres]; grupo farmacológico: $n 90$ [53 varones, 37 mujeres]). La edad promedio al inicio de las crisis epilépticas fue de 6 años (DE 4 años 4 meses) en el grupo quirúrgico y 6 años 1 mes (DE 4 años) en el grupo farmacológico. La relación de probabilidad de la ausencia de crises epilépticas fue mayor para el grupo de cirugía frente a farmacológico ( $\beta=4,24$ [intervalo de confianza (IC) $95 \%$ : 2.26-7.93], $p<0.001$ ). La cirugía no tiene ningún efecto directo sobre la puntuación total de QOLCE a 1 año $(\beta=0,24$ [IC del 95\% $-2,04$ a 2,51], $p=0,839)$ en comparación con el tratamiento farmacológico, pero tiene un efecto indirecto en el QOLCE total que fue mediado por la ausencia de crises epilépticas ( $\beta=0,92$ [IC del $95 \% 0,19-1,65], p=0,013$ ), ajustando la puntuación total de QOLCE. La cirugía tuvo un efecto directo en la mejora de la función social ( $p=0.043$ ), y un efecto indirecto en la mejora de la función física ( $p=0.016)$, la cognición $(p=0,042)$, la función social $(p=0.012)$ y el comportamiento $(p=0.032)$, mediado por la ausencia de crises epilépticas.

\section{INTERPRETACION}

En este estudio encontramos que en niños con DRE la ausencia mas significativa de crises epilépticas, lograda a través de la cirugía de epilepsia, mediaba una mejor HRQoL en comparación con el manejo farmacológico.

\section{RESUMO}

Ficar sem crises epilépticas melhora a qualidade de vida relacionada à saúde após cirurgia para epilepsia em crianças

\section{OBJETIVO}

Determinar se a cirurgia para epilepsia melhora a qualidade de vida relacionada à saude (QVRS) e se ficar sem crises epilépticas após a cirurgia media a melhora na QVRS.

\section{MÉTODO}

Este estudo de coorte multicêntrico comparou a QVRS após cirurgia para epilepsia ao manejo farmacológico em criancas com epilepsia resistente a drogas (ERD). A QVRS foi medida usando o questionário Qualidade de Vida na Epilepsia Infantil (QVEI) na linha de base e no acompanhamento após 1 ano. O mediador entre o tipo de tratamento e a QVRS foi estar sem crises epilépticas.

\section{RESULTADOS}

Duzentos e trinta e sete pacientes foram recrutados (grupo cirurgia: $n=147$ [92 do sexo masculino, 45 do sexo feminino]; grupo farmacológico: $n=90$ [53 do sexo masculino, 37 do sexo feminino]). A média de idade no início das crises foi 6 anos (DP $4 a$ am) no grupo cirúrgico e 6 anos e 1 mês (DP 4a) no grupo farmacológico. A taxa de risco de estar sem crises foi maior no grupo cirurgia versus farmacológico ( $\beta=4,24$ [intervalo de confiança a $95 \%\{I C\}: 2,26-7,93$ ], $p<0,001)$. A cirurgia não teve efeito direto no $Q V E I$ total após 1 ano $(\beta=0,24$ [IC 95\% -2,04 a 2,51], $p=0,839)$ comparada ao manejo farmacológico, mas teve efeito indireto no QVEI total que foi medido pelo fato de estar livre de crises ( $\beta=0,92$ [IC 95\% $0,19-1,65$ ], $p=0,013$ ), ajustando para o escore total QVEI na linha de base. A cirurgia teve efeito direto na melhora da função social $(p=0,043)$, e efeito indireto na melhora da função física $(p=0,016)$, cognição $(p=0,042)$, função social $(p=0.012)$ comportamento $(p=0,032)$, mediada pelo fato de estar sem crises.

\section{INTERPRETACÃ̃O}

A maior chance de ficar sem crises, atingida por meio da cirurgia, mediou a melhora na QVRS em comparação com o manejo farmacológico em crianças com ERD. 